\title{
Positron Emission Tomography in Movement Disorders
}

\author{
W. R. Wayne Martin
}

\begin{abstract}
Positron emission tomography provides a method for the quantitation of regional function within the living human brain. Studies of cerebral metabolism and blood flow in patients with Huntington's disease, Parkinson's disease and focal dystonia have revealed functional abnormalities within substructures of the basal ganglia. Recent developments permit assessment of both pre-synaptic and post-synaptic function in dopaminergic pathways. These techniques are now being applied to studies of movement disorders in human subjects.
\end{abstract}

RÉSUMÉ: La tomographie par émission de positrons dans les désordres du mouvements La tomographie par émission de positrons (PET scan) est une méthode de quantification des fonctions régionales dans le cerveau humain vivant. L'étude du métabolisme cérébral et du flot sanguin chez des patients souffrant de chorée de Huntington, de maladie de Parkinson et de dystonie focale montre des anomalies fonctionnelles à l'intérieur même des sous-structures des noyaux gris centraux. Des développements récents permettent d'étudier les fonctions pré et post-synaptiques dans les voies dopaminergiques. Ces techniques sont maintenant utilisées pour l'étude des désordres du mouvement chez l'humain.

Can. J. Neurol. Sci. 1985; 12:6-10

Positron emission tomography (PET) is a method which is used to measure the concentration of positron-emitting radiopharmaceuticals in the human brain in vivo. The use of this technique in conjunction with appropriate labelled compounds and tracer kinetic models enables the quantitation of regionally selective biochemical and physiological processes in health and disease.

This review is divided into two parts. The first section deals with the methodology which is in routine use at a number of PET centres for the measurement of cerebral metabolism and blood flow, and clinical studies which have been performed using these methods in patients with movement disorders. The second section deals with PET techniques which have been developed more recently to study functions in dopaminergic pathways in man.

\section{Cerebral Metabolism and Blood Flow}

The major energy expenditure in the brain is utilised by ion transport mechanisms for pumping sodium and potassium across neuronal membranes to maintain the electrochemical gradients necessary for the generation of action potentials (Mata et al., 1980). Aerobic glucose metabolism is responsible for the bulk of the necessary energy production. Therefore, the mapping of regional cerebral glucose metabolism (CMRG) or oxygen metabolism $\left(\mathrm{CMRO}_{2}\right)$ provides a functional image of brain activity.

The approach which has been used with PET for CMRG measurement is based on the ${ }^{14} \mathrm{C}$-2-deoxyglucose (DG) autoradiographic method developed by Sokoloff and co-workers (1977) for use in animals. This method depends on the following unique properties of DG. The bidirectional transport of DG across the blood brain barrier and its initial hexokinase-catalyzed phosphorylation is similar to that of glucose. Unlike glucose, however, the product of this reaction (DG-6-phosphate) cannot be metabolized further and is essentially trapped within the tissue. Dephosphorylation by glucose-6-phosphatase does occur, but only very slowly. The accumulation of DG-6-P in the tissue is therefore directly related to the rate of DG phosphorylation by hexokinase. An operational equation has been derived (Sokoloff et al., 1977) which expresses glucose consumption per unit mass of tissue in terms of measurable variables. This method has been used extensively with tissue autoradiography in animals for the measurement of regional CMRG in both physiological and pathological studies (for review see Sokoloff, 1981).

As originally designed, this method required direct measurement of the regional radioactivity concentration in the brain after DG administration and therefore could not be applied to

\footnotetext{
This paper is based on a special lecture presented at the Fifth Dystonia Workshop held in Calgary, Alberta on February 9-10, 1984 From the Division of Neurology, Health Sciences Centre Hospital, University of British Columbia, Vancouver Reprint requests to: Dr. Wayne Martin, Division of Neurology, Health Sciences Centre Hospital, University of British Columbia, 2211 Wesbrook Mall, Vancouver, B.C., Canada V6T IW5
} 
man. The development of PET, however, made it possible to make these measurements noninvasively. Reivich et al. (1979) demonstrated the use of this model for CMRG measurements in man with PET and the tracer ${ }^{18} \mathrm{~F}$-fluoro-2-deoxyglucose (FDG) which behaves in a similar fashion to DG. The Sokoloff model was subsequently extended to include the dephosphorylation reaction which was found to be significant for the later times employed with PET measurements (Phelps et al., 1979; Huang et al., 1980). This rnodel is now utilized for in vivo measurements of CMRG in man in numerous. PET centres throughout the world.

Cerebral oxygen extraction may be measured using inhaled ${ }^{15} \mathrm{O}$-labelled oxygen. Two major approaches have been developed for this measurement. A steady-state approach with continuous tracer inhalation has been widely used (Jones et al., 1976; Subramanyam et al., 1978; Frackowiak et al., 1980). More recently, an approach which combines the data obtained from PET measurements of cerebral blood flow and blood volume with that from a single breath inhalation of $\mathrm{O}^{15} \mathrm{O}$ has been described and validated (Mintun et al., 1984). With either of these techniques, cerebral oxygen utilization is calculated from the extraction, the measured regional cerebral blood flow, and the arterial oxygen content.

\section{Clinical Studies of Movement Disorders}

\section{Hereditary chorea}

Huntington's disease (HD) is a lethal inherited degenerative disorder characterized by the onset of chorea and personality disturbances in mid-adulthood. Pathologically there is evidence of widespread neuronal loss affecting mainly the caudate and putamen (Bruyn, 1973). This is accompanied by striatal atrophy which may be demonstrated by $x$-ray computed tomography (CT). In early HD, however, no CT changes may be evident.

Clear evidence for an abnormality of striatal glucose metabolism in HD has been obtained using PET. Kuhl et al. (1982) made PET measurements of CMRG in 13 patients with HD and compared these data with that from 40 normal subjects. The results showed a characteristic decrease in striatal glucose metabolism. Although most of their patients had CT evidence of ventricular dilatation and caudate atrophy, it was postulated that the local hypometabolism appears early, preceding bulk tissue loss. These workers also found caudate hypometabolism in 6 of 15 at-risk subjects (ages 12 to 53 years) studied. They have therefore suggested that striatal glucose utilization may be reduced in carriers of the HDgene before the onset of symptoms of $\mathrm{HD}$, but long term follow up of these will be necessary to confirm this hypothesis.

Martin et al. (1984c) have studied a group of patients with early HD who had either minimal or no evidence of caudate atrophy on CT. In comparisons of CMRG with normal subjects statistically significant hypometabolism in both caudate and putamen was demonstrated. Neither these workers nor Kuhl et al. (1982) found any significant metabolic changes in whole brain, cerebral cortex, or thalamus.

In contrast to $\mathrm{HD}$, benign hereditary chorea $(\mathrm{BHC})$ is a non-progressive inherited disorder characterized by the presence of chorea without associated dementia. The pathophysiological substrate of BHC remains unknown. PET studies in patients with this disorder have shown a spectrum of changes in striatal metabolism (Suchowersky et al., 1984). Patients with the most severe choreiform movements had caudate hypometabolism in the same range as those with HD. Mildly affected patients showed a slight decrease in caudate metabolism which was not statistically significant, but did demonstrate a much higher degree of caudate asymmetry than seen in normals.

These PET measurements of CMRG in HD and in BHC clearly demonstrate the functional involvement of the striatum in the production of choreiform movements. They do not, however, reveal which neurotransmitter systems are involved.

\section{Parkinson's disease}

The critical pathological process in Parkinson's disease (PD) is selective degeneration of nigrostriatal dopaminergic neurons leading to striatal dopamine depletion (Hornykiewicz, 1972). Although dopamine is known to be an inhibitory neurotransmitter, it is not well understood how the discrete lesion of PD affects basal ganglia functioning. Cerebral glucose utilization has been studied by several groups in animals with selective unilateral nigrostriatal lesions (Ferron et al., 1979; Kozlowski and Marshall, 1980; Wooten and Collins, 1981; Schwartz et al., 1976; Sagar and Snodgrass, 1980). The most consistent abnormality noted has been a unilateral increase in metabolism in the globus pallidus ipsilateral to a nigrostriatal lesion.

Preliminary studies of CMRG measured with PET and the FDG technique in patients with predominantly unilateral PD have been reported (Martin et al., 1984a). No consistent cortical or thalamic asymmetry was noted, but a striking degree of asymmetry was evident in the inferior region of the basal ganglia, in some patients. The affected basal ganglia (i.e., contralateral to the affected limbs) showed increased CMRG with the degree of increase corresponding approximately to the severity of disease. In the most severely affected patient a $54 \%$ increase was noted in metabolic rate on the affected side vs. the unaffected side, whereas in the least affected patient no asymmetry was noted.

Measurements of $\mathrm{CMRO}_{2}$ and $\mathrm{CBF}$ in unilateral $\mathrm{PD}$ have been reported (Leenders et al., 1983; Raichle et al., 1984). Both of these groups demonstrated asymmetric basal ganglia metabolism with increased $\mathrm{CMRO}_{2}$ evident in the basal ganglia contralateral to the affected limbs. By using a stereotactic method for anatomical localization, Raichle et al. (1984) were able to demonstrate that the globus pallidus was the sub-structure primarily responsible for the observed metabolic change.

Patients with bilateral PD have been studied. Leenders et al. (1983) found regional CBF and $\mathrm{CMRO}_{2}$ in cortical areas and basal ganglia to be similar to measurements in normal volunteers. Basal ganglia $\mathrm{CMRO}_{2}$ was lower in the bilateral PD patients than in the unilateral patients, possibly because of more prolonged duration of disease in the former group. By using the FDG method, Rougemont et al. (1983) measured CMRG in four bilateral PD patients but found no consistent difference when compared to normal control subjects. Kuhl et al. (1984) observed a moderate reduction (average $18 \%$ decrease) in global CMRG but no significant changes in striatal metabolism.

The acute effect of L-dopa on blood flow and metabolism has also been studied by the Hammersmith group (Leenders et al., 1983; Wolfson et al., 1984). In patients studied one hour after a single oral dose of L-dopa a 10-80\% increase in CBF was seen (Leenders et al., 1983). The increase in cortical areas was found to correlate with the plasma L-dopa level, but not in the basal ganglia. Increased post-Sinemet CBF has also been found by 
Raichle et al. (1984). The effect of L-dopa on $\mathrm{CMRO}_{2}$ is less clear. Leenders et al. (1983) report a decrease in $\mathrm{CMRO}_{2}$ in all brain areas following acute L-dopa administration whereas Raichle et al. (1984) report an increase. In patients on maintenance L-dopa treatment, Leenders et al. (1983) report a significant increase in basal ganglia $\mathrm{CMRO}_{2}$ as compared to the drug free state. Methodological differences relating to the necessity for maintaining a constant physiological state during sequential ${ }^{15} \mathrm{O}_{2}$ and $\mathrm{H}_{2}{ }^{15} \mathrm{O} / \mathrm{C}^{15} \mathrm{O}_{2}$ scans may well explain the apparent disagreement in $\mathrm{CMRO}_{2}$ changes.

These studies do permit several conclusions to be made concerning cerebral metabolism and blood flow in PD. Asymmetrical basal ganglia metabolism does occur in patients with predominantly unilateral PD, with changes which are similar to those seen in experimental animals with unilateral substantia nigra lesions (Wooten and Collins, 1981). Second, the administration of L-dopa produces a generalized increase in CBF. This may be secondary to increased metabolism induced by L-dopa, to a direct effect on the blood vessel wall, or to some combination of these two mechanisms. As suggested by Leenders et al. (1983), the first mechanism may be significant primarily in basal ganglia whereas the second mechanism may be significant throughout the brain. It is clearly important to control for the effects of medication in future studies of cerebral blood flow and metabolism in man.

\section{Dystonia}

The study of patients with dystonic movements affecting the head or the trunk presents a major difficulty. During the emission scan the head must be held immobile for a period ranging from 40 seconds to $60 \mathrm{~min}$. or more depending on the scanning technique used. This can prove impossible for these patients even with the short scanning times used with the CBF methodology of Raichle et al. (1983). One potential solution for the problem would be the use of a rigid head holding device such as that of Mazziotta et al. (1982) or that of Greitz et al. (1980). With our FDG studies, we have chosen instead to use pharmacological restraint with intravenous diazepam. Although a sedating medication may be expected to alter CBF and metabolism, its use with the FDG model should be acceptable provided it is not given until most of the tracer has been phosphorylated. We administer intravenous diazepam in a dose sufficient to permit comfortable head positioning and gentle restraint with a moulded thermoplastic face mask similar to that used by Ter-Pogossian et al. (1982), starting at about $30 \mathrm{~min}$. after the administration of FDG. The resulting CMRG measurement reflects primarily the cerebral metabolism integrated over the $30 \mathrm{~min}$. prior to diazepam administration and is affected little by the diazepam itself.

We have studied CMRG in a series of patients $(n=13)$ with spasmodic torticollis using this method of head positioning (Martin et al., 1984b). In these patients basal ganglia CMRG did not differ from control values, but the degree of putaminal asymmetry (9-20\%) did significantly exceed that seen in normals $(5 \pm 5 \%)$. The direction of asymmetry was not related to the direction of head turning. Although this work is still in progress, the preliminary analysis does suggest the presence of metabolic abnormalities within the basal ganglia with the major abnormality within the putamen. This is consistent with the hypothesis that the putamen is the major site of pathophysiologic involvement in dystonia (Burton et al., 1984; Narbona et al., 1984). The data suggest that in torticollis there may be a functional imbalance between the two sides rather than a unilateral abnormality in basal ganglia function.

Basal ganglia abnormalities have also been demonstrated in paroxysmal hemidystonia by Perlmutter and Raichle (1984). Their patient had normal brain anatomy on CT scan, but decreased oxygen metabolism in the basal ganglia contralateral to the affected limbs. The data showed a large area of abnormality in the basal ganglia region making it impossible to determine which substructure was responsible for the patient's symptoms.

\section{Dopaminergic Pathways}

\section{Pre-synaptic function}

It has recently become feasible with PET to visualize the distribution of dopamine in vivo. This has been made possible by the development of ${ }^{18} \mathrm{~F}$-6-fluoro-L-dopa (FD) which behaves as an analog of L-dopa (Garnett et al., 1983a). Decarboxylation of FD is thought to occur in the terminals of the nigro-striatal neurons resulting in the formation of 6-fluorodopamine which is stored in pre-synaptic vesicles. The accumulation of activity within the striatum following FD administration has been well demonstrated in both baboon (Garnett et al., 1983b) and man (Garnett et al., 1983a).

Abnormal FD uptake in patients with hemiparkinsonism has been reported (Garnett et al., 1984). The accumulation of radioactivity was found to be reduced in the basal ganglia contralateral to the affected limbs. This reduction was evident primarily in the putamen; caudate activity was also reduced, but to a lesser extent. We have demonstrated similar changes in FD studies of $P D$ patients with asymmetric clinical involvement. As pointed out by Garnett and co-workers, it is not yet known whether the reduced ${ }^{18} \mathrm{~F}$ accumulation is due to loss of dopaminergic neurons or whether it represents a functional abnormality of these cells at a relatively early stage of the disease.

The interpretation of FD studies is largely qualitative at present and does not provide quantitative data regarding the kinetics of dopa metabolism. Radioactive imaging techniques, whether tissue autoradiography in animals or "in vivo autoradiography" with PET in man, are able to determine the quantitative distribution of the radioactive label only. The identity of the compound(s) to which the label is attached cannot be determined directly from these studies alone. When ${ }^{18} \mathrm{~F}$-labelled fluorodopa is administered, several labelled metabolites will be present in brain. These include the 0 -methylated compound formed by catechol 0 -methyl transferase, as well as fluorinated homovanillic acid and dihydroxy phenylacetic acid. Ultimately, one would like to use tracer kinetic modelling techniques to make quantitative measurements of meaningful biochemical parameters. Some progress to this end has been made by the McMaster group (Garnett et al., 1980), the Hammersmith group (Leenders et al., personal communication), and ourselves (unpublished).

\section{Post-synaptic function}

The development of radio-labelled ligands which are thought to bind to receptor sites has been useful in studies for measuring receptors both in vitro and in vivo (reviewed by Snyder, 1984). 
The butyrophenone drug spiperone has been used in animal studies of dopamine receptors. Initial results using 3-N- ${ }^{11} \mathrm{C}$ methylspiperone (NMSP) for imaging dopamine receptors in man have been reported (Wagner et al., 1983). These studies demonstrated that NMSP was localized in the basal ganglia where it is known that there is a high density of dopamine receptors. This uptake is blocked by the administration of other unlabelled dopamine receptor antagonists in excess, suggesting that NMSP does indeed bind specifically to dopamine receptors.

Studies with NMSP in a series of thirty normal subjects have now been presented (Wong et al., 1984). Serial studies performed for 2 hours after injections demonstrated progressively increasing caudate and putamen activity and simultaneously a progressive decrease in cerebellar activity. The ratio of caudate to cerebellar activity was found to decrease significantly with age in males, but not in females. This binding was felt to represent an age and sex related decrease in dopamine receptor density.

The use of tracer kinetic modelling techniques in conjunction with such radio-labelled ligands should permit quantitative analysis of drug-binding sites in the brain in vivo. A suitable model has been developed by Mintun and co-workers (1984). The model makes use of repeated measurements of local radioactivity with PET following tracer administration to characterize the dynamic interplay between the ligand and its receptor. This data is combined with PET measurements of other local physiological variables such as blood volume and blood flow to determine the binding potential of the tissue which is equivalent to the product of the number of binding sites and the binding affinity. These workers have demonstrated the utility of this model with ${ }^{18} \mathrm{~F}$-spiperone to measure binding potential and spiperone permeability in baboons. The same techniques may be readily applied to similar studies in man.

\section{Conclusions}

Studies of cerebral metabolism and blood flow with PET in movement disorders have demonstrated focal abnormalities secondary to altered neuronal function in the basal ganglia. Objective measurements of parameters concerned with in vivo regional cerebral function in man were previously unavailable. Newer techniques have now emerged for the study of both pre-synaptic and post-synaptic function in dopaminergic pathways. These methods, currently in their infancy, are just starting to be applied to patient studies. It should be possible to employ similar techniques to investigate other neurotransmitter systems once suitably labelled tracer compounds are available. The feasibility of imaging opiate receptors (Frost et al., 1984) and muscarinic acetylcholine receptors (Eckelman et al., 1984) has been demonstrated in man. This technology will provide a vast potential for the study of pathophysiology of numerous neurological disorders in human subjects.

\section{ACKNOWLEDGEMENTS}

Supported in part by the Dystonia Medical Research Foundation.

\section{REFERENCES}

Bruyn GW (1973) Neuropathological changes in Huntington's chorea. In: Huntington's Chorea, Barbeau A, Chase TN, Paulson GW (eds.) Raven Press, New York pp. 399-403.

Burton K, Farrell K, Li D, Calne DB (1984) Lesions of the putamen and dystonia: CT and magnetic resonance imaging. Neurology 34: 962-965.

Eckelman WC, Reba RC, Rzeszotarski WJ, Gibson RE, Hill T, Holman BL, Budinger T, Conklin JJ. Eng R, Grissom MP (1984) External imaging of cerebral muscarinic acetylcholine receptors. Science 223: 291.292.

Ferron A. DesRosiers MH, de Montigny C, Bosler O. Reader TA, Descarries $L$ (1979) Effects of unilateral destruction of the nigrostriatal dopamine system on local cerebral glucose utilization in adult rat. Soc. Neuro. Sci. Abstr. 5: 70.

Frackowiak RSJ, Lenzi G-L, Jones T, Heather JD (1980) Quantitative measurement of regional cerebral blood flow and oxygen metabolism in man using ${ }^{15} \mathrm{O}$ and positron emission tomography: theory, procedure, and normal values. J. Comput. Assist. Tomogr. 4: 727-736.

Frost JJ, Dannals RF, Ravert HT, Wilson AA, Wong DF. Links JM, Burns HD, Kuhar MJ, Snyder SH, Wagner HN Jr (1984) Imaging opiate receptors with positron emission tomography. J. Nucl. Med. 25: P73.

Garnett ES, Firnau G, Nahmias C (1983a) Dopamine visualized in the basal ganglia of living man. Nature 305: 137-138.

Garnett S, Firnau G, Nahmias C, Chirakal R (1983b) Striatal dopamine metabolism in living monkeys examined by positron emission tomography. Brain Res. 280: 169-171.

Garnett ES, Firnau G, Nahmias C. Sood S, Belbeck L (1980) Bloodbrain barrier transport and cerebral utilization of dopa in living monkeys. Am. J. Physiol. 238: 318-327.

Garnett ES, Nahmias C, Firnau G (1984) Central dopaminergic pathways in hemiparkinsonism examined by positron emission tomography. Can. J. Neurol. Sci. 11: 174-179.

Greitz T, Bergstrom M, Boethius, Kingsley D, Ribbe T (1980) Head fixation system for integration of radiodiagnostic and therapeutic procedures. Neuroradiology 19: 1-6.

Hornykiewicz O (1972) Neurochemistry of parkinsonism. In: Handbook of Neurochemistry 7, A. Lajtha, (ed.) Plenum Press, New York pp. 465-501.

Huang S-C, Phelps ME, Hoffman EJ, Sideris K, Selin CJ, Kuh! DE (1980) Noninvasive determination of local cerebral metabolic rate of glucose in man. Am. J. Physiol. 238: E69-E82.

Jones T, Chesler DA, Ter-Pogossian MM (1976) The continuous inhalation of oxygen- 15 for assessing regional oxygen extraction in the brain of man. Br. J. Radiol. 49: 339-343.

Kozlowski MR, Marshall JF (1980) Plasticity of $\left[{ }^{14} \mathrm{C}\right] 2$-deoxy-d-glucose incorporation into neostriatum and related structures in response to dopamine neuron damage and apomorphine replacement. Brain Res. 197: 167-183.

Kuhl DE, Metter EJ, Reige WH (1984) Patterns of local cerebral glucose utilization determined in Parkinson's disease by the ${ }^{18}$ F]Fluorodeoxyglucose method. Ann. Neurol. 15: 419-424.

Kuhl DE, Phelps ME, Markham CH, Metter EJ, Riege WH, Winter J (1982) Cerebral metabolism and atrophy in Huntington's disease determined by ${ }^{18} \mathrm{FDG}$ and computed tomographic scan. Ann. Neurol. 12: 425-434.

Leenders K, Wolfson L, Gibbs J, Wise R, Jones T, Legg N (1983) Regional cerebral blood flow and oxygen metabolism in Parkinson's disease and their response to L-dopa. J. Cereb. Blood Flow Metabol. 3 (Suppl. 1): 488-489.

Martin WRW, Beckman JH, Calne DB, Adam MJ, Harrop R, Rogers JG, Ruth TJ, Sayre Cl, Pate BD (1984a) Cerebral glucose metabolism in Parkinson's disease. Can. J. Neurol. Sci. 11: 169-173.

Martin WRW, Hayden M, Calne DB, Beckman J, Bergstrom M, Harrop R, Sayre C, Pate BD, Adams M. Ruth T, Rogers J (1984b) Positron emission tomography in the study of disorders of the basal ganglia. Can. J. Neurol. Sci. 11: 326.

Martin WRW, Hayden MR, Suchowersky O, Beckman J, Adam M, Ammann W, Bergstrom M, Harrop R, Rogers J, Ruth T, Sayre C, Pate BD (1984c) Striatal metabolism in Huntington's disease and in benign hereditary chorea. Ann. Neurol. 16: 126.

Mata M, Fink DJ, Gainer H, Smith CB, Davidsen L, Savaki H, Schwartz WJ, Sokoloff L (1980) Activity-dependent energy metabolism in rat posterior pituitary primarily reflects sodium pump activity. J. Neurochem. 34: 213-215. 
Mazziotta JC, Phelps ME, Meadors AK, Ricci A, Winter J, Bentson JR (1982) Anatomical localization schemes for use in positron computed tomography using a specially designed headholder. J. Comput. Assist. Tomogr. 6(4): 848-853.

Mintun MA, Raichle ME (1984) Kinetic measurements are necessary for description of brain receptors with PET. J. Nucl. Med. 25: P72.

Mintun MA, Raichle ME, Kilbourne MR, Wooten GF, Welch MJ (1984) A quantitative model for the in vivo assessment of drug binding sites with positron emission tomography. Ann. Neurol. 15: 217-227.

Mintun MA, Raichle ME, Martin WRW, Herscovitch P (1984) Brain oxygen utilization Measured with 0-15 radiotracers and positron emission tomography. J. Nucl. Med. 25: 177-187.

Narbona J, Obeso JA, Tunon T, Martinez-Lage JM, Marsden CD (1984) Hemi-dystonia secondary to localised basal ganglia tumour. J. Neurol. Neurosurg. Psych. 47: 704-709.

Perlmutter JS, Raichle ME (1984) Pure hemidystonia with basal ganglion abnormalities on positron emission tomography. Ann. Neurol. 15: 228-233.

Phelps ME, Huang SC, Hoffman EJ, Selin C, Sokoloff L, Kuhl DE (1979) Tomographic measurement of local cerebral glucose metabolic rate in humans with (F-18)2-fluoro-2-deoxy-D-glucose:validation of method. Ann. Neurol. 6: 371-388.

Raichle ME, Martin WRW, Herscovitch P, Mintun MA, Markham J (1983) Brain blood flow measures with intravenous $\mathrm{H}_{2}{ }^{15} \mathrm{O}$. II. Implementation and validation. J. Nucl. Med. 24: 790-798.

Raichle ME, Perlmutter JS, Fox PT (1984) Parkinson's disease: metabolic and pharmacological approaches with positron emission tomography. Ann. Neurol. (Suppl.) 15: 131-132.

Reivich M, Kuhl D, Wolf A, Greenberg J, Phelps M, Ido T, Casella V, Fowler J, Hoffman E, Alavi A, Som P, Sokoloff L (1979) The $\left[{ }^{18} \mathrm{~F}\right]$ fluorodeoxyglucose method for the measurement of local cerebral glucose utilization in man. Circ. Res. 44: 127-137.

Rougemont D, Baron JC, Collard P, Bustany P, Comar D, Agid Y (1983) Local cerebral metabolic rate of glucose (ICMRGlc) in treated and untreated patients with Parkinson's disease. J. Cereb. Blood Flow Metabol. 3 (Suppl. 1): 504-505.

Sagar SM, Snodgrass SR (1980) Effects of Substantia Nigra Lesions on Forebrain 2-deoxy-glucose Retention in the Rat. Brain Res. 185: 335-348.
Schwartz WJ, Sharp FR, Gunn RH, Evarts EV (1976) Lesions of ascending dopaminergic pathways decrease forebrain glucose utilization. Nature 261: 155-157.

Snyder SH (1984) Drug and neurotransmitter receptors in the brain. Science 224: 22-31.

Sokoloff L (1981) Localization of functional activity in the central nervous system by measurement of glucose utilization with radioactive deoxyglucose. J. Cereb. Blood Flow Metabol. 1: 7-36.

Sokoloff L, Reivich M, Kennedy C, Des Rosiers MH, Patlak CS, Pettigrew KD, Sakurada O, Shinohara M(1977)The $\left[{ }^{14} \mathrm{C}\right]$ deoxyglucose method for the measurement of local cerebral glucose utilization: theory, procedure, and normal values in the conscious and anesthetized albino rat. J. Neurochem. 28: 897-916.

Subramanyam R, Alpert NM, Hoop B Jr, Brownell GL, Taveras JM (1978) A model for regional cerebral oxygen distribution during continuous inhalation of ${ }^{15} \mathrm{O}_{2}, \mathrm{C}^{15} \mathrm{O}$, and $\mathrm{C}^{15} \mathrm{O}_{2}$. J. Nucl. Med. 19: 48-53.

Suchowersky O, Hayden M, Martin WRW, Li DK, Bergstrom M, Harrop R, Rogers J, Sayre C, Pate BD (1984) Benign hereditary chorea: clinical, radiological and PET findings. Can. J. Neurol. Sci. 11: 329.

Ter-Pogossian MM, Ficke DC, Hood JT Sr, Yamamoto M, Mullani NA (1982) PETT VI: A positron emission tomograph utilizing cesium fluoride scintillation detectors. J. Comput. Assist. Tomogr. 6(1): 125-133.

Wagner HN Jr, Burns HD, Dannals RF, Wong DF, Langstrom B, Duelfer T, Frost JJ, Ravert HT, Links JM, Rosenbloom SB, Lukas SE, Kramer AV, Kuhar MJ (1983) Imaging dopamine receptors in the human brain by positron tomography. Science 221: 1264-1266.

Wolfson L, Leenders KL, Jones T (1984) Parkinson's disease and Sinemet treatment alter regional cerebral blood flow and oxygen metabolism. Neurology 34 (Suppl.1): 115.

Wong, DF, Wagner HN Jr, Dannals RF, Frost JJ, Ravert HV, Links JM, Folstein MF, Jensen BA, Kuhar MJ, Toung JT (1984) The effects of age on dopamine receptors measured by positron tomography in the living human brain. J. Nucl. Med. 25: P73.

Wooten GF, Collins RC (1981) Metabolic effects of unilateral lesions of the substantia nigra. J. Neurosci. 1: 285-291. 